\title{
Образованность, школы, книжная культура в Восточном Средиземноморье в IV-VII вв. (Антиохия, Берит, Кесария, Газа)
}

\author{
Н.Н. Болгов, А.М. Болгова, И.В. Денисова, Ю.В. Бузанаков \\ Белгородский государственный национальный исследовательский университет, \\ Россия, 308007, г. Белгород, ул. Студенческая, 14 \\ E-mail: bolgov@bsu.edu.ru
}

\begin{abstract}
Аннотация. В работе рассматривается состояние и эволюция школ и состояние образованности, роль книжной культуры в Восточном Средиземноморье ранневизантийского времени (IV-VII вв.) в контексте культурного континуитета между античностью и Средневековьем на примере городов Сиро-Палестинского региона Антиохии, Берита, Кесарии и Газы. Помимо внутренней истории школ, делаются общие наблюдения над спецификой ситуации в каждом из указанных центров. Весь позднеантичный мир с середины VI в. стал проявлять признаки медиевализации знания, эволюции картины мира, что находилось в связи с другими процессами завершения развития античной цивилизации (прекращение реального муниципального самоуправления, рост этатизма, углубление христианизации, влияние оживившихся местных этно-конфессиональных традиций в регионах). Тем не менее сохранение высоких стандартов грамотности, книг и школ продолжалось до вступления Византии в «Темные века».
\end{abstract}

Ключевые слова. Книги, школы, образованность, Поздняя античность, Ранняя Византия, Восточное Средиземноморье.

Благодарности: исследование выполнено при финансовой поддержке РФФИ в рамках научного проекта № 19-19-50284 «Книжная культура и образованность в Средиземноморье в IV-VII вв.».

Для цитирования: Болгов Н.Н., Болгова А.М., Денисова И.В., Бузанаков Ю.В. 2020. Образованность, школы, книжная культура в Восточном Средиземноморье в IV-VII вв. (Антиохия, Берит, Кесария, Газа). Via in tempore. История. Политология, 47 (4): 714-726. DOI: $10.18413 / 2687-0967-2020-47-4-714-726$.

\section{Education, schools, book culture in the East Mediterranean in the 4th-7th cent. A. D. (Antihoch, Berit, Caesaria, Gaza)}

\author{
Nikolay N. Bolgov, Anna M. Bolgova, Irina V. Denisova, Yuri V. Buzanakov \\ Belgorod National Research University, \\ 14 Studencheskaja St., Belgorod, 308007, Russia \\ E-mail: bolgov@bsu.edu.ru
}

\begin{abstract}
Annotation. The work examines the state and evolution of schools and the state of education, the role of book culture in the Eastern Mediterranean of the early Byzantine time (IV-VII centuries) in the context of the cultural continuity between antiquity and the Middle Ages, using the cities of the Syro-Palestinian region of Antioch, Berita, Caesarea and Gaza as an example. In addition to the internal history of schools, general observations are made on the specifics of the situation in each of these centers. The entire late antique world from the middle of the VI century. began to show signs of mediaevalization of knowledge, the evolution of the picture of the world, which was associated with other processes of completing the development of ancient civilization (the termination of real municipal self-government, the growth of statism, the deepening of Christianization, the influence of revived local ethno-religious traditions in the regions). However, maintaining high standards of literacy, books, and schools continued until Byzantium entered the Dark Ages.
\end{abstract}


Keywords. Books, schools, education, Late Antiquity, Early Byzantium, Eastern Mediterranean.

Acknowledgments: The research was carried out with the financial support of the Russian Foundation for Basic Research within the framework of the scientific project No. 19-19-50284 «Book culture and education in the Mediterranean in the IV-VII centuries».

For citation: Bolgov N.N., Bolgova A.M., Denisova I.V., Buzanakov Yu.V. 2020. Education, schools, book culture in the East Mediterranean in the 4th-7th cent. A. D. (Antihoch, Berit, Caesaria, Gaza). Via in tempore. History and political science, 47 (4): 714-726 (in Russian). DOI: 10.18413/2687-0967-2020-474-714-726.

Сохранение высших школ, высокого уровня образованности, почти повсеместной грамотности, развитой книжной культуры в Поздней античности позволило заложить основы для развития средневековой книжности и учености, чем была обеспечена преемственность между античной и средневековой культурой.

Наличие хорошего образования в Ранней Византии было важнейшим фактором карьерного продвижения в условиях высокой вертикальной социальной мобильности. При этом, помимо «профессионального» для будущих бюрократов юридического образования, [Collinet, 1925] важнейшую роль играла риторика, формировавшая «универсальные компетенции» [Cribiore, 2007, p. 225-228].

Предшествующие исследования позднеантичной книжной культуры [Wilson, 1975, p. 1-15.] и образованности [Самодурова, 1984, с. 478-503; Кривушин, Кривушина, 2002; Гольцева, 2005, с. 22-27; Безрогов, 2008; Лемерль, 2012; Ведешкин, 2019, с. 348-363; Тюленев, 2018, с. 40-53; Тюленев, 2019; Уоттс, 2019, с. 306-338; Downey, 1958, p. 297-319; Cameron, 1969, 7-29; Watts, 2008] производились либо применительно к отдельным регионам латинского Запада или Ранней Византии, либо с ориентацией на наследие отдельных авторов. При этом как отдельные регионы, так и отдельные авторы до сих пор не были предметом специального исследования, особенно в отечественной науке, в данном контексте [Болгова, 2015, с. 172-177; Лопатина, 2017].

Данная статья продолжает исследование, начатое в работе, посвященной состоянию образованности и школ в важнейших интеллектуальных центрах [Болгова, 2015б, c. 50-53] - Константинополе, Афинах и Александрии [Болгов, 2020].

Антиохия. Важнейшим интеллектуальным центром позднеантичного Восточного Средиземноморья была Антиохия - метрополия Востока. Подъем язычества и античной науки в Антиохии наблюдается в период правления императора Юлиана, который восстановил храм в честь Траяна и учредил там библиотеку. Однако она была сожжена его преемником императором Иовианом. Некоторые антиохийцы пытались спасти книги из огня, выбрасывая их на землю и прикрепляя к стенам, чтобы желающие могли их почитать (Suid. I 401).

Антиохия славилась риторической школой. В 1-й пол. IV в. здесь жил ритор Ульпиан, у которого обучался Проэресий (Eunap. Vit. soph. 487). Оттуда происходил один из самых знаменитых риторов поздней античности - Либаний, где он основал собственную школу. Его речи отличались изяществом и обаянием, были связаны с интересом к древности. В школе обучались студенты со всего Восточного Средиземноморья [Cribiore, 2007, p. 99; Болгова, 2015a, с. 51-55; Болгова, 2018, с. 43-71]. От него дошло множество речей и писем [Болгов, 2015, с. 3-5], в которых он развивал античную ораторскую традицию, ориентируясь на Демосфена. Либаний пользовался покровительством императора Юлиана, а его влияние в Антиохии было настолько сильным, что он даже выступал посредником между муниципалитетом и имперской властью (Liban. Or. XVI, XVII). Однако латинским языком Либаний полноценно не владел и для чтения писем Симмаха заказывал их переводы на греческий [Уоттс, 2019]. Его учеником был знаменитый христианский богослов и епископ св. Иоанн Златоуст, которому он хотел даже передать свою школу (Soz. HE. 
VIII. 2; Socr. HE. VI. 3). Другом Либания был антиохийский грамматик и поэт Дифил [Kaster, 1997, p. 273].

Во 2-й пол. V в. здесь был известен ритор Мосх, которому покровительствовал Гиларий, представитель местной знати, впоследствии ставший философом и учеником Прокла (Damasc. Vit. Is. 91).

Из Антиохии происходил один из наиболее известных историков IV в. Аммиан Марцеллин, классически образованный и написавший римскую историю на латыни [Удальцова, 1974, с. 9-10].

В VI в. здесь прославился популярный хронограф Иоанн Малала [Croke, 1990, p. 1-27]. В Антиохии располагалась резиденция Комита Востока, и там были государственные архивы, сохранявшие много документов, которыми пользовался хронист (Malal. Chron. XVIII. 29).

В конце VI в. в городе творил церковный историк Евагрий Схоластик [Удальцова, 1969 , с. 63-72], в качестве источников использовавший труды своих старших современников Зосима и Прокопия Кесарийского (Evagr. HE. III. 40; IV. 12). За свою литературную деятельность он удостоился почетного консульства и квестуры от императоров Тиверия II и Маврикия (Evagr. HE. VI. 24).

Также в VII в. был известен автор «Хроники» Иоанн Антиохийский [История Византии, 1967, т. 1, с. 50].

Помимо язычества здесь была сильная христианская традиция. Крупный богословский центр был основан Лукианом Антиохийским в III в. В Антиохийской школе во главу угла ставилось буквальное толкование Священного Писания и заучивание, обучение велось на греческом языке [Саврей, 2012]. Учеником Лукиана был крупнейший ересиарх Арий [свящ. Владимир (Шмалий), 2009, с. 226-227].

Антиохийская богословская школа породила несторианство и монофизитство. К антиохийской школе принадлежал ересиарх Несторий. Крупнейшим теологом был епископ $\mathrm{V}$ в. Феодор Мопсуэстийский. Из Антиохии происходил и церковный историк и богослов Феодорит Киррский [Сидоров, 2009, с. 525-530]. Там же жил епископ конца IV в. Евагрий, друживший со св. Иеронимом, переведший на латынь «Житие св. Антония» Афанасия Великого и оставивший ряд других трактатов (Hier. De vir. ill. 125). B V-VI вв. Антиохия стала центром борьбы несторианства и монофизитства. В V в. патриарший престол занимал пронесторианский Иоанн Антиохийский (Socr. HE. VII. 34; Cyr. Scyth. V. Euth. 31-32). B VI в. крупнейшим представителем монофизитства был Север Антиохийский (Evagr. HE. III. 33), получивший классическое образование в Александрии и дружный с епископом и церковным историком Захарией Митиленским [Болгова, Болгов, 2019, с. 105-136].

Но также сильные позиции имело и ортодоксальное православие. В IV в. известны Отцы Церкви, обучавшиеся в Антиохии: епископ Евсевий Эмесский - друг Евсевия Никомедийского и ученик Евсевия Кесарийского, обучавшийся философии и светским наукам в Александрии (Soz. HE. III. 6), а также Кирилл Иерусалимский [свящ. Михаил (Желтов), 2018, с. 299-318]. Учеником Евсевия Эмесского, изгнанного паствой за глубокие знания математики (Socr. HE. II. 9), стал Диодор Тарсийский, однако в светских науках он был мало сведущ (Hier. De vir. ill. 119). Также там учились теологи Исаак Амидский, Феодор Антиохийский, Павлин Антиохийский, Мохим Месопотамский, чьи сочинения были в V в. известны Геннадию Массилийскому (Gen. Mass. De vir. ill. 3, 12, 66, 71).

Наибольшую славу получил антиохийский святитель Иоанн Златоуст, ученик ритора Либания, сочетавший в своих речах христианское содержание с классической формой. Позднее Златоуст перехал в Константинополь, где обличал пороки знати и боролся с ересями, в том числе с арианством. Своими проповедями он вызвал гнев императрицы Евдоксии, жены императора Аркадия, из-за чего был низложен и сослан в ссылку [Кулаковский, 2003, т. 1, с. 187-201]. Популярность Иоанна была такова, что его осуждение вызвало чуть ли не восстание в Константинополе, которое нашло отражение даже в языче- 
ских источниках (Zos. V. 23-24), а его речи читал св. Иероним (Hier. De vir. ill. 129), а в VII в. - Исидор Севильский (Isid. Hisp. De vir. ill. 19).

Во 2-й половине VI в. был известен церковный канонист Иоанн Схоластик (503-577), автор «Номоканона», с 565 г. - константинопольский патриарх.

Антиохия пострадала от разрушительного землетрясения в 526 г., вследствие чего была переименована в Теополь (Malal. Chron. XVII. 16), а затем была разгромлена персидским шахом Хосроем в 540 г. (Рroc. В.P. II. 7-10, 14). Хотя Юстиниан ее восстановил (Proc. De aed. III. 10), однако город захирел и культурная жизнь в нем постепенно угасла. Точку античному городу поставило арабское нашествие первой половины VII в. [Downey, 1961, p. 577-578].

Берит. Крупнейшая юридическая школа была в Берите (совр. Бейрут) [Collinet, 1925; Болгова; Болгов, 2013, с. 306-311]. В ней преподавали Домнин, Скилиаций, Кирилл, Патрикий, Демосфен, Евдоксий, Евксен, Ямвлих, Леонтий, Аноним (старший). Согласно законодательству императора Юлиана, профессоров права назначала городская курия, что утверждалось императором, последнее было отменено при Юстиниане. В VI в. в юридической школе обучение велось на латинском и греческом языке, в течение 5 лет студенты должны были тонко постигнуть законодательство Юстиниана [Липшиц, 1984, с. 358-371]. Император Юстиниан усовершенствовал систему обучения. Из 50 книг Дигест надо было изучать 36. Основным учебником были «Институции», составленные на основе «Институций» Гая, «Ответов» Павла и других античных комментаторов, изучавшихся до этой реформы, строго разделенные по разделам (Dig. Just. Const. Deo auct. 5, 11; Const. Omn. 2-5; Const. Tant. 1-8). Студентам разъясняли различные разделы курса на основе индексов к «Дигестам».

Берит в «Дигестах» назван в качестве одного из главных юридических центров (Dig. Just. Const. Omn. 7). Его отлично знал в V в. Нонн Панополитанский, посвятивший его прославлению отдельную книгу (песню) «Деяний Диониса» (Non. Dionys. Lib. XLI). В качестве составителей «Дигест» упоминаются юристы и правоведы Дорофей, Анатолий - представитель юридической династии, которые атрибутированы как происходящие из Бейрута и преподававшие там. Также названы еще несколько десятков имен юристов без указания их города (Dig. Just. Const. Tant. 9, 11). Известны у современников были и профессора Бейрутской школы VI в., составившие комментарии к «Дигестам», Кирилл и Патрикий. Возможно, из Бейрута происходил и известный юрист и преподаватель константинопольской правовой школы Феофил, составлявший первое издание «Кодекса Юстиниана» вместе с Дорофеем, написавший греческий парафраз и схолии к «Дигестам».

В Берите в середине V в. изучал юриспруденцию церковный историк Созомен [Treadgold, 2010, p. 146].

В конце V - начале VI вв. у профессора права Леонтия (Zach. V. Sev. 62) обучались юридическим наукам Захария Ритор и будущий монофизитский патриарх Севир Антиохийский. Это отражено в «Жизнеописании Севира» Захарии, оставившего свидетельства и о культурной жизни в городе. В частности, Севир много изучал классическую литературу, а в городе должна была быть крупная библиотека юридических книг (Zach. V. Sev. 11, 59, $62,63,67)$. Среди студентов-юристов было укоренено язычество, и они имели множество книг языческого содержания, которые переписывались в частных скрипториях и были широко распространены. Одним из известных языческих философов, астрологов и теургов в городе был Леонтий, вынужденный впоследствии обратиться в христианство. В домах ученых города засвидетельствованы частные библиотеки (Zach. V. Sev. 74-91).

Христианские студенты организовывались в группы филопонов и самостоятельно изучали Священное Писание и христианских авторов после занятий в школе, особенно Отцов Церкви - св. Григория Богослова, Василия Великого, Кирилла Александрийского, Иоанна Златоуста. Однако эти книги не были распространены в Берите, и Захария привез их с собой. Но также у некоторых были частные собрания христианских книг. Лидером группы был студент, философ и аскет Евагрий (Zach. V. Sev. 62-73, 86, 111). Впослед- 
ствии многие филопоны приняли монашество (Zach. V. Sev. 121-124). По инициативе Захарии и Севира и при поддержке епископа и со стороны властей филопоны разгромили очаг язычества в городе, изъяв и подвергнув публичному сожжению много языческих книг, а их владельцев, к которым принадлежали и знатные люди города, заставили обратиться в христианство (Zach. V. Sev. 86-94).

Кесария Палестинская. Одним из главных интеллектуальных центров Палестины была Кесария Палестинская [Ващева, 2005, с. 13-25; Ващева, 2005a, с. 72-80; Болгова, 2015c, с. 84-88; Schemmel, 1925, S. 1277-1280], которая выступала в качестве административного центра региона, разделившегося с начала V в. на три провинции [Болгова, Болгов, Агаркова, 2013, с. 78-83].

В Кесарии Оригеном еще в III в. была учреждена крупнейшая библиотека, для которой Ориген привез с собой свои книги из Александрии, а также мог собирать книги в других регионах. В библиотеке содержались не только христианские труды, но также работы языческих писателей - как греческих, так и восточных, в том числе многих философов. Среди них были работы Александра Полигистора, Иосифа Флавия, Плутарха, Платона, Филона Александрийского, пифагорейцев, стоиков и многих других. В этой библиотеке находилась «Гексапла» - главный труд Оригена, который представлял параллельный свод текстов Ветхого Завета на иврите и 4 греческих перевода. Эти книги читал и использовал для своих работ Евсевий Кесарийский в IV в. [Carriker, 2003, p. 5, 8м9].

Помимо библиотеки, Оригеном была учреждена крупная философская школа, где изучали все философские направления, за исключением эпикурейцев, превратив Кесарию в важнейший центр оригенизма. Ее слушателем был св. Григорий Тауматург. Продолжил традиции школы Памфил, собиравший книги и расширивший библиотеку [Carriker, 2003, p. 13]. Согласно Исидору Севильскому, библиотека Памфила включала 30 тысяч томов (Isid. Hisp. Etym. VI. 6). Под его руководством в библиотеке переписывали античные книги из свитков в кодексы. Многие тексты он переписывал собственноручно, составив полный каталог книг библиотеки (Euseb. HE. VI. 32), в том числе 25 томов сочинений Оригена, которые в конце IV в. имел св. Иероним, считая себя из-за этого богатым, как Крез (Hier. De vir. ill. 75). Важный вклад Памфил внес в редакцию и издание Священного Писания, составив его критический текст [Carriker, 2003, p. 15-16]. В обучении Памфил использовал философские тексты, в частности Плотина и Порфирия [Carriker, 2003, p. 13].

Его учеником был Евсевий Кесарийский - крупнейший церковный историк времен Константина I, основоположник жанра «Церковной истории» и автор «Хроники», опиравшейся на сведения античных и древневосточных авторов [Treadgold, 2010, p. 369], а также ряд полемических и биографических работ, о которых сообщает св. Иероним (Hier. De vir. ill. 81). Помимо греческого, Евсевий изучил латинский язык в школе [Carriker, 2003, p. 17-18]. Евсевий наследовал заведование библиотекой после смерти Памфила. Школа в Кесарии подверглась гонениям при императоре Диоклетиане, пострадала и библиотека - многие христианские сочинения были уничтожены [Carriker, 2003, p. 21]. При библиотеке, видимо, был крупный скрипторий - к Евсевию обращался император Константин, прося прислать копии Библии (Euseb. V. Const. IV. 36-37).

При императоре Констанции множество трактатов на разные темы написал епископ Кесарии Акакий (Hier. De vir. ill. 98). Учеником Акакия и его преемником стал церковный историк Геласий Кесарийский [Ващева, 2009, с. 38-42], писавший изящным языком, его знал св. Иероним (Hier. De vir. ill. 130).

Во 2-й пол. IV в. в Кесарии действовала риторическая школа оратора Феспесия, где получали образование Евзой и Григорий Назианзин (Hier. De vir. ill. 113). Также из Кесарии Палестинской происходил проязыческий ритор Акакий, подражавший древним ораторам в своих речах, чье искусство высоко ценилось современниками и местами затмевало даже Либания (Eunap. V. soph. 497). Евзой впоследствии, став епископом города, приложил большие усилия для восстановления библиотеки, написав ряд трактатов, которые 
были широко известны (Hier. De vir. ill. 113). В библиотеке хранились как книги в папируcax, так и кодексах под руководством епископов Акакия и Евзоя [Carriker, 2003, p. 23-25]. Некоторые кодексы в кесарийской библиотеке (Синаитский, Ватиканский) сохранились к настоящему времени [Carriker, 2003, p. 23]. Библиотекой Кесарии пользовались Гиларий из Пуатье и Евсевий Верцеллийский во 2-й пол. IV в., найдя там сочинения Оригена. В конце IV - начале V вв. много времени в библиотеке провел Иероним, изучая там Оригена. В конце V в. там преподавал Прокопий Газский, а в VI в. выходцем данной школы стал самый знаменитый ранневизантийский историк Прокопий Кесарийский [Carriker, 2003, p. 26-28], получивший глубокое классическое образование, широко знавший древних авторов [Cameron, 2005, p. 1-4]. Представителем академического богословия в Кесарии был Иоанн Грамматик Кесарийский, автор многочисленных работ против ересей, живший в начале VI в. [Сидоров, 1988, p. 81-99].

Кесарийская библиотека погибла в начале VII в. при пожаре [Ващева, 2005, с. 25].

Газа. Еще один важный интеллектуальный центр Палестины - Газа [Болгов, Болгова, 2013, с. 262-267], являвшаяся крупным языческим центром еще на протяжении V в. Там существовало два основных направления: связанные с классической традицией светские школы и богословские центры, опиравшиеся на монашескую традицию.

Газа - родина церковного историка V в. Созомена [Treadgold, 2010, p. 145].

Во 2-й половине V в. в Газе процветала школа христианского ритора и софиста Энея Газского, оставившего диалог «Феофраст» и сборник писем, который был связан с александрийской школой и, вероятно, обучался там у неоплатоника Гиерокла Александрийского [Манохин, 2018, с. 29-34]. Он хорошо знал как классические труды Платона и неоплатоников, так и святоотеческие тексты христианской традиции [Болгова, Болгов, 2016, c. 146-150].

Младшим современником Энея и, возможно, его студентом был ритор Прокопий Газский, который продолжил традиции Энея. Он оставил после себя корпус писем, несколько панегириков, в том числе императору Анастасию, несколько речей, экфрасисов и монодий [Болгова, 2014, с. 101-107]. Кроме того, ему приписывают комментарии и толкования на книги Ветхого и Нового Заветов, в том числе в новой форме катен [Манохин, 2018a, с. 138-140]. В школе Прокопия было сочетание классической и христианской традиции - там будущие епископы и священники обучались красноречию на примерах из античной мифологии [Болгова, 2014, с. 101-107].

В Газе во времена Анастасия был известен грамматик Зосим Газский (Аскалонский), написавший комментарии к Демосфену и Лисию (Suid. Z 169). Его иногда соотносят с языческим историком этого же времени Зосимом, автором «Новой истории» [Болгов, 2010, c. 4-46]. Современниками Зосима и Прокопия являлся латинский грамматик Гиерий, уехавший преподавать латынь в Антиохию вместе с греческими грамматиками Алипием и Стефаном [Манохин, 2018a, с. 193]. Примерно в это же время жил и филолог Тимофей Газский, также являющийся автором трактата «О животных» [История Византии, 1967, т. 1, c. 384], получивший образование в александрийской риторической школе Гораполлона.

Продолжателем и непосредственным преемником Прокопия стал его ученик ритор Хорикий Газский, оставивший после себя корпус речей и декламаций, посвященных античным сюжетам и даже языческим традициям [Bolgova, Bolgov, 2013, p. 2-3; Болгова, Болгов, 2011, с. 65-71]. Одно из наиболее известных его произведений - «Апология мимов», где он выступает в качестве защитника античного театрального искусства, вызывавшего в целом осуждение Церкви. В то же время сам Хорикий придерживался христианского мировоззрения и сам в мифы не верил, оставив экфрасисы на храмы города [Downey, 1958, p. 297-319].

В VI в. в Газе творил поэт Иоанн Газский [Лопатина, 2019, с. 98-100], первый в ранневизантийской литературе представитель христианского символизма, аллегорически толковавший античные символы. 
Другим направлением стала монашеская, богословская и агиографическая традиция в Газе. В окрестностях города было более полутора десятков монастырей [Hirschfeld, 2004, p. 61-88], наиболее известные - монастырь св. Илариона, монастырь Петра Ивера, монастырь Севера, монастырь аввы Серида. В последнем в VI в. был создан свод правил на основе переписки старцев монастыря Варсануфия и Иоанна, а также корпус сочинений аввы Дорофея Газского [Курбанов, 2017, с. 20-22, 30-32], который был учеником Прокопия Газского [игум. Дионисий (Шлёнев), 2010, с. 32-43]. В общежительных городских монастырях Газы, кроме послушаний и молитвы, монахи начинают изучать Священное Писание, а впоследствии и прочие науки [игум. Кирилл (Илюхин), 2007, с. 170-186].

Одним из наиболее известных представителей газской христианской школы конца V - 1-й пол. VI вв. был монофизитский епископ Митилены Захария Ритор (Схоластик), получивший образование в Александрии и Бейруте, а также имевший прочные связи с Константинополем [Winkelmann, 1980, p. 182]. Наиболее крупные его произведения «Церковная история» [The Syriac Chronicle, 1899], диалог «Аммоний» [Zacharias Mytilene, 2012, p. 93-176] и «Жизнь Севира» [Грацианский, 2013, с. 702-703; Two Early Lives of Severos, 2013], также ряд других житий монофизитских подвижников. Есть предположение, что Захария являлся братом Прокопия Газского [Манохин, 2018а, с. 86].

Другим монофизитским писателем этого времени был Иоанн Руф, ученик Петра Ивера, который был монахом и посвятил свои работы истории антихалкидонского сопротивления в Палестине [Манохин, 2018а, с. 87].

Итак, главнейшие интеллектуальные центры восточно-средиземноморского мира Константинополь, Афины, Александрия, Антиохия, Берит, Кесария Палестинская, Газа. Несмотря на то, что первые три занимали ведущее положение, рассмотренные здесь города центра достойно дополняют их.

Конец единому средиземноморскому культурному пространству положили арабские завоевания, в ходе которых многие интеллектуальные центры Восточной Римской империи - Александрия, Антиохия, Берит, Кесария, Газа - были поглощены иной, мусульманской культурой, установившей господство над Восточным Средиземноморьем. Это привело к общей провинциализации и медиевализации византийской культуры, ее изоляции от западного мира. Византийская греческая культура ушла из Сирии, Палестины, Египта. Это создало условия для окончательного возвышения Константинополя в культурной сфере. Тем не менее книги и интеллектуалы в огромной мере содействовали сохранению относительно единого культурного пространства Поздней античности в канун наступления Средневековья.

\section{Список литературы}

1. Безрогов В.Г. 2008. Традиции ученичества и институт школы в древних цивилизациях. М., Памятники исторической мысли, 460.

2. Болгов Н.Н. 2010. Зосим - последний античный историк. Зосим. Новая история. Белгород, БелГУ: 4-46.

3. Болгов Н.Н. 2020. Книжная культура, школы и образованность в Восточном Средиземноморье в IV-VII вв. (Константинополь. Афины. Александрия). Византийский временник, в печати.

4. Болгов Н.Н. 2015. Письма Либания в русских переводах. Мир поздней античности. Документы и материалы. Вып. 3. Белгород, 66.

5. Болгов Н.Н., Болгова А.М. 2019. Александрийские школы V в. по «Философской истории» Дамаския. Иресиона. Античный мир и его наследие. Белгород. Вып. VI.: 105-136. 
6. Болгова А.М. 2015. Интеллектуальные центры поздней античности и «академическая мобильность» студентов. Научные ведомости БелГУ. Серия История. Политология. Вып. 35. 13 (210): 50-53.

7. Болгова А.М. 2015c. Кесарийская школа как феномен переходной эпохи от античности к Византии. Педагогика и образование в системе научного знания. Белгород: 84-88.

8. Болгова А.М. 2014. Прокопий Газский: ритор и богослов. Проблемы истории, филологии, культуры. 2: 101-107.

9. Болгова А.М. 2018. Ранневизантийские портреты: риторы, софисты, философы. Белгород, БелГУ, 404.

10. Болгова А.М. 2015a. Школа Либания по его письмам. III Сиротенковские чтения. Армавир: 51-55.

11. Болгова А.М. 2015б. Школы Ранней Византии: к истории изучения в отечественной историографии. Иресиона. Античный мир и его наследие. Белгород. Вып. IV.: 172-177.

12. Болгова А.М., Болгов Н.Н. 2013. Позднеантичный Берит в Финикии и его юридическая школа. Государство и общество: взаимодействие и противостояние. Воронеж, ВГУ: 306-311.

13. Болгова А.М., Болгов Н.Н. 2012. Провинциальная Газа в Палестине и ее писатели позднеантичного времени. Столица и провинция: история взаимоотношений. Воронеж, ВГУ: 262-267.

14. Болгова А.М., Болгов Н.Н. 2011. Ритор Хорикий и Газская школа. Научные ведомости БелГУ. История. Политология. Экономика. Информатика. Вып. 18.7 (102): 65-71.

15. Болгова А.М., Болгов Н.Н. 2016. Эней Газский против неоплатоников и оригенистов: к изучению наследия Энея в отечественной науке. 1917-2017: уроки столетия. Материалы ежегодных Митрофановских церковно-исторических чтений. Воронеж: 146-150.

16. Болгова А.М., Болгов Н.Н., Агаркова Ю.Н. 2013. К истории Кесарии Палестинской в ранневизантийское время. Кондаковские чтения - IV. Белгород: 78-83.

17. Ващева И.Ю. 2005. Кесария Палестинская в III - первой половине VII вв. Вестник Нижегородского университета им. Н.И. Лобачевского. Серия История. Нижний Новгород. Вып. 1 (4): 13-25.

18. Ващева И.Ю. 2005а. Образование в Кесарии Палестинской в III - первой половине VII вв. Актуальные проблемы исторической науки и творческое наследие С.И. Архангельского. Нижний Новгород: 72-80.

19. Ващева И.Ю. 2009. Церковный историк Геласий Кесарийский. Научные ведомости БелГУ. Серия История. Политология. Экономика. Информатика. Вып. 12. 15 (70): 38-42.

20. Ведешкин М.А. 2019. «Учителя-душегубы»: образование и апостасия в Поздней Римской империи. Диалог со временем. 66: 348-363.

21. Гольцева О.Е. 2005. Светские и духовные образовательные центры в Ранней Византии (IV-VII вв.). Наш Анабасис. Вып. 2. Нижний Новгород: 22-27.

22. Грацианский М.В. 2013. Захария Ритор. Православная энциклопедия. Т. 19: 702-703.

23. Игум. Дионисий (Шлёнев). 2010. Дорофей Газский. Православная энциклопедия. T. 16: $32-43$.

24. Игум. Кирилл (Илюхин). 2007. История христианского образования. Православный собеседник. Казань, 2 (15): 170-186.

25. История Византии. 1967. В 3 т. Под общ. ред. С.Д. Сказкина. Т. 1. М., Наука, 566.

26. Кривушин И.В., Кривушина Е.С. 2002. Византийская школа. Иваново, ИвГУ, 88.

27. К Кулаковский Ю.А. 2003. История Византии. В 3 т. Т. І: 395-518 годы. СПб., Алетейя. 512.

28. Курбанов А.В. 2017. Повседневная жизнь ранневизантийской киновии (на примере монастыря аввы Серида). Дисс. канд. истор. наук. 07.00.03. Белгород, 288.

29. Лемерль П. 2012. Первый византийский гуманизм. Замечания и заметки об образовании и культуре в Византии от начала до Х века. СПб., Свое издательство, 492.

30. Липшиц Е.Э. 1984. Юридические школы и развитие правовой науки. Культура Византии IV - первая половина VII в. М., Наука: 358-371.

31. Лопатина М.Ю. 2019. Иоанн Газский: классические мотивы ранневизантийской поэзии. Византийское содружество: традиции и смена парадигм: тезисы докладов XXII Всероссийской научной сессии византинистов РФ, Екатеринбург, 24-28 сентября 2019 г. Екатеринбург, 98-100. 
32. Лопатина М.Ю. 2017. Современная зарубежная историография истории Поздней античности и Ранней Византии (1990-2015 гг.). Мир Поздней античности. Документы и материалы. Вып. 8. Отв. ред. Н.Н. Болгов. Белгород, БелГУ, 110.

33. Манохин Я.В. 2018. «Феофраст» и «Аммоний». Отражение ранневизантийской полемики между христианством и античным язычеством в литературном наследии риторской школы Газы. Научные ведомости БелГУ. Серия История. Политология. 2018. Вып. 45. 1: 29-34.

34. Манохин Я.В. 2018а. Ранневизантийская Газа - христианский интеллектуальный центр в Палестине. Дисс. канд. истор. наук. 07.00.03. Белгород, 274.

35. Саврей В.Я. 2012. Антиохийская школа в истории христианской мысли. М., МГУ, 290.

36. Самодурова 3.Р. 1984. Школы и образование. Культура Византии. IV - первая половина VII в. М., Наука: 478-503.

37. Свящ. Владимир Шмалий. 2009. Арий. Православная энциклопедия. Т. 3: 226-227.

38. Свящ. Михаил Желтов. 2018. Кирилл. Православная энциклопедия. Т. 34: 299-318.

39. Сидоров А.И. 2009. Богословские школы древней Церкви. Православная энциклопедия. Т. 5: 525-530.

40. Сидоров А.И. 1988. Иоанн Грамматик Кесарийский (к характеристике византийской философии в VI в.). Византийский временник. Т. 49 (74): 81-99.

41. Тюленев В.М. 2019. Римская школа на позднеантичном латинском Западе (Южная Галлия и Италия в V - первой половине VI в.). Иваново, ИвГУ, 224.

42. Тюленев В.М. 2018. Эллинская словесность и ученость на латинском Западе V - первой половины VI вв. Cursor Mundi: человек Античности, Средневековья и Возрождения. 10: 40-53.

43. Удальцова 3.В. 1974. Идейно-политическая борьба в Ранней Византии (по данным историков IV-VII вв.). М., Наука, 388.

44. Удальцова 3.В. 1969. К вопросу о мировоззрении византийского историка VI в. Евагрия. Византийский временник. Т. 30 (55): 63-72.

45. Уоттс Э. 2019. Образование в поздней античности. Общение, мысль и социализация. Hypothecai. Вып. 3: 306-338.

46. Bolgova A., Bolgov N. 2013. The Crossroads of Epochs and Cultures: Choricius of Gaza as a mirror of continuity. L'Ecole de Gaza: espace litteraire et identite culturelle dans l'Antiquite Tardive. Paris, College de France: 2-3.

47. Cameron Al. 1969. The last days of the Academy in Athens. Proceeding of the Cambridge Philological Society. 15: 7-29.

48. Cameron Av. 2005. Procopius and the Sixth Century. London, New York, UP, 380.

49. Carriker A.J. 2003. The Library of Eusebius of Caesarea. Leiden, Boston, Brill, 312.

50. Collinet P. 1925. Histoire de l'ecole de droit de Beyrouth. Paris, L'Efevr, 365.

51. Cribiore R. 2007. The school of Libanius in Late Antique Antioch. Princeton, UP, 384.

52. Croke B. 1990. Malalas, the man and his work. Studies in John Malalas. Sydney, BA: 1-27.

53. Downey G. 1961. A History of Antioch in Syria from Seleucus to the Arab Conquest. Princeton, UP, 512.

54. Downey G. 1958. The Christian School of Palestine: A Chapter in Literary History. Harvard Library Bulletin. 12: 297-319.

55. Hirschfeld Y. 2004. The Monasteries of Gaza: An Archaeological Review. Christian Gaza in Late Antiquity. Leiden, Brill: 61-88.

56. Kaster R. 1997. Guardians of Language: The Grammarian and Society in Late Antiquity. Berkeley, Los Angeles, Oxford, UP, 422.

57. Schemmel F. 1925. Die Schule von Caesarea in Palästina. Philologische Wochenschrift. 45: $1277-1280$.

58. The Syriac Chronicle, known as that of Zachariah of Mitylene. 1899. Trans. F.J. Hamilton, E.W. Brooks. London, KK, 390.

59. Treadgold W. 2010. The Early Byzantine Historians. London, Palgrave MacMillan, 488.

60. Two Early Lives of Severos, Patriarch of Antioch, 2013. Trans. with an intr. and notes by S. Brock and B. Fitzgerald. Liverpool, BE, 210.

61. Watts E. 2088. City and School in Late Antique Athens and Alexandria. Berkeley, UCP, 368.

62. Wilson N. 1975. Books and readers in Byzantium. Byzantine Books and Bookmen. Washington, Ed., 1-15. 
63. Winkelmann F. 1980. Die östlichen Kirche in der Epoche der christologischen Auseinandersetzung. Berlin, Verlag, 322.

64. Zacharias Mytilene. Ammonius. Aeneas of Gaza. Theophrastus. 2012. Trans. by J. Dillon and D. Russel. Gen. ed. R. Sorabji. Bristol, Ed., 93-176.

\section{Referenses}

1. Bezrogov V.G. 2008. Tradicii uchenichestva i institut shkoly v drevnih civilizaciyah [Apprenticeship Traditions and School Institute in Ancient Civilizations]. M., Pamyatniki istoricheskoj mysli, 460 (in Russian).

2. Bolgov N.N. 2010. Zosim - poslednij antichnyj istorik [Zosimus - the last ancient historian]. Zosim. Novaya istoriya [Zosimus. New history]. Belgorod, BelGU: 4-46 (in Russian).

3. Bolgov N.N. 2020. Knizhnaya kul'tura, shkoly i obrazovannost' v Vostochnom Sredizemnomor'e v IV-VII vv. (Konstantinopol'. Afiny. Aleksandriya) [Book culture, schools and education in the Eastern Mediterranean in the IV-VII centuries (Constantinople. Athens. Alexandria)]. Vizantijskij vremennik [Byzantine temporary], v pechati [in print].

4. Bolgov N.N. 2015. Pis'ma Libaniya v russkih perevodah [Letters of Libanius in Russian translations]. Mir pozdnej antichnosti. Dokumenty i materialy [World of late antiquity. Documents and materials]. Vyp. 3. Belgorod, 66 (in Russian).

5. Bolgov N.N., Bolgova A.M. 2019. Aleksandrijskie shkoly V v. po «Filosofskoj istorii» Damaskiya [Alexandrian schools of the 5th century on the «Philosophical History» of Damascius]. Iresiona. Antichnyj mir i ego nasledie [Iresione. Ancient world and its heritage]. Vyp. VI. Belgorod: 105-136 (in Russian).

6. Bolgova A.M. 2015. Intellektual'nye centry pozdnej antichnosti i «akademicheskaya mobil'nost'» studentov [Intellectual centers of late antiquity and «academic mobility» of students]. Nauchnye vedomosti BelGU. Seriya Istoriya. Politologiya [Scientific reports of BelSU. Series History. Political science]. № 13 (210). Vyp. 35. Belgorod: 50-53 (in Russian).

7. Bolgova A.M. 2015c. Kesarijskaya shkola kak fenomen perekhodnoj epohi ot antichnosti k Vizantii [Caesarean school as a phenomenon of the transitional era from antiquity to Byzantium]. Pedagogika i obrazovanie $\mathrm{v}$ sisteme nauchnogo znaniya [Pedagogy and education in the system of scientific knowledge]. Belgorod: 84-88 (in Russian).

8. Bolgova A.M. 2014. Prokopij Gazskij: ritor i bogoslov [Procopius of Gaza: rhetorician and theologian]. Problemy istorii, filologii, kul'tury [Problems of history, philology, culture]. 2: 101-107 (in Russian).

9. Bolgova A.M. 2018. Rannevizantijskie portrety: ritory, sofisty, filosofy [Early Byzantine portraits: rhetoricians, sophists, philosophers]. Belgorod, BelGU, 404 (in Russian).

10. Bolgova A.M. 2015a. Shkola Libaniya po ego pis'mam [School of Libania according to his letters]. III Sirotenkovskie chteniya [III Sirotenko readings]. Armavir: 51-55 (in Russian).

11. Bolgova A.M. 2015b. Shkoly Rannej Vizantii: $\mathrm{k}$ istorii izucheniya v otechestvennoj istoriografii [Schools of Early Byzantium: on the history of studying in Russian historiography]. Iresiona. Antichnyj mir i ego nasledie [Irecione. Ancient world and its heritage]. Vyp. IV. Belgorod: 172-177 (in Russian).

12. Bolgova A.M., Bolgov N.N. 2013. Pozdneantichnyj Berit v Finikii i ego yuridicheskaya shkola [Late Antique Berith in Phoenicia and his Law School]. Gosudarstvo i obshchestvo: vzaimodejstvie i protivostoyanie [State and society: interaction and confrontation]. Voronezh, VGU: 306-311 (in Russian).

13. Bolgova A.M., Bolgov N.N. 2012. Provincial'naya Gaza v Palestine i ee pisateli pozdneantichnogo vremeni [Provincial Gaza in Palestine and its writers of late antiquity]. Stolica i provinciya: istoriya vzaimootnoshenij [Capital and Province: Relationship History]. Voronezh, VGU: 262-267 (in Russian).

14. Bolgova A.M., Bolgov N.N. 2011. Ritor Horikij i Gazskaya shkola [Ritor Choricios and the Gaza School]. Nauchnye vedomosti BelGU. Istoriya. Politologiya. Ekonomika. Informatika [Scientific reports of BelSU. Story. Political science. Economy. Computer science]. Vyp. 18, 7 (102): 65-71 (in Russian).

15. Bolgova A.M., Bolgov N.N. 2016. Enej Gazskij protiv neoplatonikov i origenistov: k izucheniyu naslediya Eneya v otechestvennoj nauke [Aeneas of Gaza against Neoplatonists and Origenists: to study the heritage of Aeneas in Russian science]. 1917-2017: uroki stoletiya. Materialy ezhegodnyh Mitrofanovskih cerkovno-istoricheskih chtenij [1917-2017: the lessons of the century. Materials of the annual Mitrofanov Church-Historical Readings]. Voronezh: 146-150 (in Russian).

16. Bolgova A.M., Bolgov N.N., Agarkova Yu.N. 2013. K istorii Kesarii Palestinskoj v rannevizantijskoe vremya [To the history of Caesarea Palestine in the early Byzantine time]. Kondakovskie chteniya - IV [Kondakov readings - IV]. Belgorod: 78-83 (in Russian). 
17. Vashcheva I.Yu. 2005. Kesariya Palestinskaya v III - pervoj polovine VII v. [Caesarea of Palestine in the III - first half of the VII century]. Vestnik Nizhegorodskogo universiteta im. N.I. Lobachevskogo. Seriya Istoriya [Bulletin of the Nizhny Novgorod University. N.I. Lobachevsky. History Series]. Vyp. 1 (4). Nizhniy Novgorod: 13-25 (in Russian).

18. Vashcheva I.Yu. 2005a. Obrazovanie v Kesarii Palestinskoj v III - pervoj polovine VII vv. [Education in Caesarea Palestine in the III - first half of the VII centuries]. Aktual'nye problemy istoricheskoj nauki i tvorcheskoe nasledie S.I. Arhangel'skogo [Actual problems of historical science and the creative heritage of S.I. Arkhangelsky]. Nizhniy Novgorod: 72-80 (in Russian).

19. Vashcheva I.Yu. 2009. Cerkovnyj istorik Gelasij Kesarijskij [Church historian Gelasius of Caesarea]. Nauchnye vedomosti BelGU. Seriya Istoriya. Politologiya. Ekonomika. Informatika [Scientific reports of BelSU. Series History. Political science. Economy. Computer science]. Vyp. 12, 15 (70): 38-42 (in Russian).

20. Vedeshkin M.A. 2019. «Uchitelya-dusheguby»: obrazovanie i apostasiya v Pozdnej Rimskoj imperii [«Murderer Teachers»: Education and Apostasy in the Late Roman Empire]. Dialog so vremenem [Dialogue over time]. 66: 348-363 (in Russian).

21. Gol'ceva O.E. 2005. Svetskie i duhovnye obrazovatel'nye centry v Ranney Vizantii (IV-VII vv.) [Secular and spiritual educational centers in Early Byzantium (IV-VII centuries)]. Nash Anabasis [Our Anabasis]. Nizhniy Novgorod, Vyp. 2: 22-27 (in Russian).

22. Gracianskij M.V. 2013. Zahariya Ritor [Zachariah Ritor]. Pravoslavnaya enciklopediya [Orthodox Encyclopedia]. T. 19: 702-703 (in Russian).

23. Igum. Dionisij (Shlyonev). 2010. Dorofej Gazskij [Dorotheus of Gaza]. Pravoslavnaya enciklopediya [Orthodox Encyclopedia]. T. 16: 32-43 (in Russian).

24. Igum. Kirill (Ilyuhin). 2007. Istoriya hristianskogo obrazovaniya [History of Christian Education]. Pravoslavnyj sobesednik [Orthodox interlocutor]. Kazan', 2 (15): 170-186 (in Russian).

25. Istoriya Vizantii [History of Byzantium]. 1967. V 3 t. Pod obshch. red. S.D. Skazkina. T. 1. M., Nauka, 566 (in Russian).

26. Krivushin I.V., Krivushina E.S. 2002. Vizantiyskaya shkola [Byzantine school]. Ivanovo, IvGU, 88 (in Russian).

27. Kulakovskij Yu.A. 2003. Istoriya Vizantii [History of Byzantium]. V 3 t. T. I: 395-518 gody. SPb., Aletejya. 512 (in Russian).

28. Kurbanov A.V. 2017. Povsednevnaya zhizn' rannevizantijskoj kinovii (na primere monastyrya avvy Serida) [Everyday life of early Byzantine kinovia (on the example of the monastery of Abba Serid)]. Diss. kand. istor. nauk. 07.00.03. Belgorod, 288 (in Russian).

29. Lemerl' P. 2012. Pervyj vizantijskij gumanizm. Zamechaniya i zametki ob obrazovanii i kul'ture $v$ Vizantii ot nachala do X veka [The first Byzantine humanism. Remarks and notes on education and culture in Byzantium from the beginning to the X century]. SPb., Svoe izdatel'stvo, 492 (in Russian).

30. Lipshic E.E. 1984. Yuridicheskie shkoly i razvitie pravovoj nauki [Law schools and the development of legal science]. Kul'tura Vizantii IV - pervaya polovina VII v. [The culture of Byzantium IV - the first half of the VII century]. M., Nauka: 358-371 (in Russian).

31. Lopatina M.Yu. 2019. Ioann Gazskij: klassicheskie motivy rannevizantijskoj poezii [John of Gazi: Classical Motives of Early Byzantine Poetry]. Vizantijskoe sodruzhestvo: tradicii i smena paradigm: tezisy dokladov XXII vserossijskoj nauchnoj sessii vizantinistov RF, Ekaterinburg, 24-28 sentyabrya 2019 g. [The Byzantine Commonwealth: Traditions and Paradigm Shift: Abstracts of the XXIIth All-Russian Scientific Session of the Byzantinists of the Russian Federation, Yekaterinburg, September 24-28, 2019]. Ekaterinburg, 98-100 (in Russian).

32. Lopatina M.Yu. 2017. Sovremennaya zarubezhnaya istoriografiya istorii Pozdney antichnosti i Ranney Vizantii (1990-2015 gg.) [Modern foreign historiography of the history of Late Antiquity and Early Byzantium (1990-2015)]. Mir Pozdney antichnosti. Dokumenty i materialy [World of Late Antiquity. Documents and materials]. Vyp. 8. Otv. red. N.N. Bolgov. Belgorod, BelGU, 110 (in Russian).

33. Manohin Ya.V. 2018. «Feofrast» i «Ammonij». Otrazhenie rannevizantijskoj polemiki mezhdu hristianstvom i antichnym yazychestvom v literaturnom nasledii ritorskoj shkoly Gazy $[\langle$ Feofrast» and «Ammonius». Reflection of the Early Byzantine polemic between Christianity and ancient paganism in the literary heritage of the rhetorical school of Gaza]. Nauchnye vedomosti BelGU. Seriya Istoriya. Politologiya [Scientific reports of BelSU. Series History. Political science]. 2018. Vyp. 45, 1: 29-34 (in Russian). 
34. Manohin Ya.V. 2018a. Rannevizantijskaya Gaza - hristianskij intellektual'nyj centr v Palestine [Early Byzantine Gaza - Christian Intelligent Center in Palestine]. Diss. kand. istor. nauk. 07.00.03. Belgorod, 274 (in Russian).

35. Savrej V.Ya. 2012. Antiohijskaya shkola v istorii hristianskoj mysli [Antioch School in the History of Christian Thought]. M., MGU, 290 (in Russian).

36. Samodurova Z.R. 1984. Shkoly i obrazovanie [Schools and Education]. Kul'tura Vizantii. IV - pervaya polovina VII vv. [The culture of Byzantium. IV - the first half of the VII centuries]. M., Nauka: 478-503 (in Russian).

37. Svyashch. Vladimir Shmalij. 2009. Arij [Arius]. Pravoslavnaya enciklopediya [Orthodox Encyclopedia]. T. 3: 226-227 (in Russian).

38. Svyashch. Mihail Zheltov. 2018. Kirill [Kyrillos]. Pravoslavnaya enciklopediya [Orthodox Encyclopedia]. T. 34: 299-318 (in Russian).

39. Sidorov A.I. 2009. Bogoslovskie shkoly drevnej Cerkvi [Theological Schools of the Ancient Church]. Pravoslavnaya enciklopediya [Orthodox Encyclopedia]. T. 5: 525-530 (in Russian).

40. Sidorov A.I. 1988. Ioann Grammatik Kesarijskij (k harakteristike vizantijskoj filosofii v VI v.) [John the Grammar of Caesarea (on the characteristic of Byzantine philosophy in the 6th century)]. Vizantijskij vremennik [Byzantine temporary]. T. 49 (74): 81-99 (in Russian).

41. Tyulenev V.M. 2019. Rimskaya shkola na pozdneantichnom latinskom Zapade (Yuzhnaya Galliya i Italiya v V - pervoj polovine VI vv.) [Roman school in the late ancient Latin West (South Gaul and Italy in the V - first half of the VI century)]. Ivanovo, IvGU: 224 (in Russian).

42. Tyulenev V.M. 2018. Ellinskaya slovesnost' i uchenost' na latinskom Zapade V - pervoj poloviny VI vv. [Hellenic literature and scholarship in the Latin West of the 5th - first half of the 6th century]. Cursor Mundi: chelovek Antichnosti, Srednevekov'ya i Vozrozhdeniya [Cursor Mundi: Man of Antiquity, Medieval and Renaissance]. 10: 40-53 (in Russian).

43. Udal'cova Z.V. 1974. Idejno-politicheskaya bor'ba v Rannej Vizantii (po dannym istorikov IV-VII vv.) The ideological and political struggle in Early Byzantium (according to historians of the $4^{\text {th }}-$ 7th centuries). M., Nauka, 388 (in Russian).

44. Udal'cova Z.V. 1969. K voprosu o mirovozzrenii vizantijskogo istorika VI v. Evagriya [On the worldview of a Byzantine historian of the 6th century Evagrius]. Vizantijskij vremennik [Byzantine temporary]. T. 30 (55): 63-72 (in Russian).

45. Watts E. 2019. Obrazovanie v pozdnej antichnosti. Obshchenie, mysl' i socializaciya [Education in late antiquity. Communication, thought and socialization]. Hypothecai. Vyp. 3: 306-338 (in Russian).

46. Bolgova A., Bolgov N. 2013. The Crossroads of Epochs and Cultures: Choricius of Gaza as a mirror of continuity. L'Ecole de Gaza: espace litteraire et identite culturelle dans l'Antiquite Tardive. Paris, College de France: $2-3$.

47. Cameron Al. 1969. The last days of the Academy in Athens. Proceeding of the Cambridge Philological Society. 15: 7-29.

48. Cameron Av. 2005. Procopius and the Sixth Century. London, New York, UP, 380.

49. Carriker A.J. 2003. The Library of Eusebius of Caesarea. Leiden, Boston, Brill, 312.

50. Collinet P. 1925. Histoire de l'ecole de droit de Beyrouth. Paris, L'Efevr, 365.

51. Cribiore R. 2007. The school of Libanius in Late Antique Antioch. Princeton, UP, 384.

52. Croke B. 1990. Malalas, the man and his work. Studies in John Malalas. Sydney, BA: 1-27.

53. Downey G. 1961. A History of Antioch in Syria from Seleucus to the Arab Conquest. Princeton, UP, 512.

54. Downey G. 1958. The Christian School of Palestine: A Chapter in Literary History. Harvard Library Bulletin. 12: 297-319.

55. Hirschfeld Y. 2004. The Monasteries of Gaza: An Archaeological Review. Christian Gaza in Late Antiquity. Leiden, Brill: 61-88.

56. Kaster R. 1997. Guardians of Language: The Grammarian and Society in Late Antiquity. Berkeley, Los Angeles, Oxford, UP, 422.

57. Schemmel F. 1925. Die Schule von Caesarea in Palästina. Philologische Wochenschrift. 45: $1277-1280$.

58. The Syriac Chronicle, known as that of Zachariah of Mitylene. 1899. Trans. F.J. Hamilton, E.W. Brooks. London, KK, 390.

59. Treadgold W. 2010. The Early Byzantine Historians. London, Palgrave MacMillan, 488. 
60. Two Early Lives of Severos, Patriarch of Antioch, 2013. Trans. with an intr. and notes by S. Brock and B. Fitzgerald. Liverpool, BE, 210.

61. Watts E. 2088. City and School in Late Antique Athens and Alexandria. Berkeley, UCP, 368.

62. Wilson N. 1975. Books and readers in Byzantium. Byzantine Books and Bookmen. Washington, Ed., 1-15.

63. Winkelmann F. 1980. Die östlichen Kirche in der Epoche der christologischen Auseinandersetzung. Berlin, Verlag, 322.

64. Zacharias Mytilene. Ammonius. Aeneas of Gaza. Theophrastus. 2012. Trans. by J. Dillon and D. Russel. Gen. ed. R. Sorabji. Bristol, Ed., 93-176.

\section{ИНФОРМАЦИЯ ОБ АВТОРАХ}

Болгов Николай Николаевич, доктор исторических наук, профессор кафедры всеобщей истории Белгородского государственного национального исследовательского университета, г. Белгород, Россия

Болгова Анна Михайловна, кандидат педагогических наук, доцент кафедры всеобщей истории Белгородского государственного национального исследовательского университета, г. Белгород, Россия

Денисова Ирина Викторовна, кандидат исторических наук, доцент кафедры всеобщей истории Белгородского государственного национального исследовательского университета, г. Белгород, Россия

Бузанаков Юрий Владимирович, аспирант кафедры всеобщей истории Белгородского государственного национального исследовательского университета, г. Белгород, Россия

\section{INFORMATION ABOUT THE AUTHORS}

Nikolai N. Bolgov, Doctor of Historical Sciences, Professor of the Department of General History, Belgorod State National Research University, Belgorod, Russia

Anna M. Bolgova, Candidate of Pedagogy, Associate Professor of the Department of General History, Belgorod State National Research University, Belgorod, Russia

Irina V. Denisova, Candidate of Historical Sciences, Associate Professor of the Department of General History, Belgorod State National Research University, Belgorod, Russia

Yuri V. Buzanakov, Postgraduate Student, Department of General History, Belgorod State National Research University, Belgorod, Russia 